\title{
The Art of Time Travel: A Bigger Picture
}

\section{Emily Caddick Bourne ${ }^{1}$ and Craig Bourne ${ }^{2}$}

${ }^{1}$ University of Hertfordshire

Hatfield, Hertfordshire

United Kingdom of Great Britain and Northern Ireland

${ }^{2}$ University of Hertfordshire

de Havilland campus, Hatfield AL10 9AB

United Kingdom of Great Britain and Northern Ireland

Article info

CDD: 115

Received: 22.03.2017; Accepted: 24.03.2017

DOI: http://dx.doi.org/10.1590/0100-6045.2017.V40N1.EC

Keywords

Time travel

Causal loop

McCall's puzzle

Value of works of art

\begin{abstract}
In his contribution to the second part of this special issue, Storrs McCall criticizes the solution to his puzzle that we put forward in the first part of the issue. In this paper, we expand on our solution and defend it from his objections.
\end{abstract}

In discussing (in Bourne and Caddick Bourne (2016)) McCall's puzzle of the artist who copies his paintings from their reproductions, and before proposing four responses to this particular puzzle, we raise the example of a different, more familiar puzzle, involving a causal loop where a time traveller builds a time machine based on plans they deliver, using the time machine, to their younger self. McCall (2017) focusses on this example, and his response to our paper falls into two parts: an objection to the construction of the case involving plans for a time machine, and a restatement of his assertion that the case of the paintings introduces a special puzzle concerning artistic creativity which has not been solved.

Manuscrito - Rev. Int. Fil. Campinas, v. 40, n. 1, pp. 281-287, jan.-mar. 2017. 
These points are connected because McCall thinks, mistakenly, that it is through the example of plans for a time machine that we propose to resolve his puzzle.

McCall objects that this example as we construct it - which we took to be representative of one of what he calls the "traditional "paradoxes of time travel"' (2010, p.648) - is 'not a clearly defined paradox at all'. McCall offers no further explanation. Is it that he thinks the example is not clearly defined, or is it that he thinks the conditions for a paradox are not met? Either way, we can add clarification to the example by distinguishing between two types it might take. In the first type, the causal loop involves an event of drawing up the plans. For instance: the time traveller receives the plans from her older self; she builds the time machine; looking at the plans after completing the machine, she sees that they are faded and knows that her younger self needs them to be clearer; she draws up the plans (either by looking at the plans or by looking at the time machine itself); she delivers the plans to her younger self. In the second type, there is no event of drawing up the plans. For instance: the time traveller receives the plans from her older self; she builds the time machine; she picks the plans up from her desk, gets in the time machine and delivers the plans to her younger self. (The loop must also include events which make it the case that the plans are delivered in the state the time traveller receives them in.) In both cases, no act of designing the plans takes place, in the sense of an originating event which brings the plans into existence in a way that does not already depend on what the plans are like. In the second case, no act of producing the physical object that is the plans takes place.

One reason why someone might be suspicious about the latter type of case is the spontaneous (in the sense of unprompted) existence of an object (the plans). We take it that this is what McCall has in mind when he asks, 'So, do the plans magically jump into existence from nowhere?' This question is asked rhetorically and meant as an objection. But it is not an objection: it is the very puzzle that would characterize the loop as paradoxical by the standards of the traditional 'paradoxes' of time travel. In this type of case, backwards time travel would enable a causal loop which leaves the question of where the plans come from. Further, the issue of the plans' existence is not so different from that which arises in the first type of case. Although in that type of case, the loop does include an event 
of drawing up the plans, that event nevertheless has the existence of the plans as a causal antecedent. The difference between the cases lies in answers which may be given, from within the loop, to the question of where the plans came from. One person may say 'I drew them up' and the other may not, for instance. But in neither case is there an origin for the plans which explains their existence in the loop.

A similar discussion can be had about McCall's example, about which one could ask 'So, does the causally interrelated pair of reproductions and paintings magically jump into existence from nowhere?' McCall's case will involve a causal loop similar to that in some version of the plans and time machine case. Since some stages in the life of the reproductions are not described, which version is not explicitly defined. But let us assume that the reproductions are copied from the paintings, making the causal relationships analogous to the case where the time machine is built based on the plans, and the plans are drawn up based on looking at the time machine. McCall would have to think that at least the first type of case we describe of plans for a time machine is well-defined, if he thinks his own example is.

But set all this aside. The crucial point is that our suggestion was not that the answer to McCall's puzzle lies in considering an example of the plans for a time machine. On the contrary, our interest in the example was to identify how McCall's case differs. In McCall's original paper (2010) there is no explanation of $w h y$ artistic creativity would introduce a further puzzle not contained in traditional examples of backwards time travel. Our original paper provided this. (In that sense, the use of the example was supposed to be friendly to McCall.) McCall says, 'The role of artworks in my article is crucial. The creation of a genuine artwork, as opposed to plans for a time machine, requires artistic creativity. And where is this to be found in Bourne and Caddick Bourne's example?' Answer: nowhere. For our point was precisely that if McCall's is, as he takes it to be, a novel puzzle, that is because the focus on artistic creativity introduces conditions within the causal loop which are absent from other cases.

We went on to give four ways of responding to the particular puzzle, concerning creativity, that arises in McCall's case. The first three deny some aspect of McCall's supposed set-up. For instance, one denies that the paintings are aesthetically valuable (or, to put it in the terms of

Manuscrito - Rev. Int. Fil. Campinas, v. 40, n. 1, pp. 281-287, jan.-mar. 2017. 
McCall's reply, that they are 'magnificent'), and another maintains that the paintings are aesthetically valuable, but denies that this entails creativity. To McCall's question 'Where is the artistic creativity to be found?', such responses answer 'It isn't'. Perhaps we could say - to advance a reply on McCall's behalf - that any genuine solution to his problem would have to give a more positive answer than that. But only if the description we are asked to accept of the scenario is sustainable, and there is reason to be cautious about that: the collection of stipulations by which McCall hopes to constitute the puzzle are vulnerable in a way the stipulations that constitute some other time travel puzzles are not. McCall's stipulations are not just about what exists, or what caused what, but are also about value. To make the case work, we must accept not just that the paintings look a certain way, but that they have artistic worth. Given that there is an open question about what properties and processes ground artistic value, it is not clear why one would accept, on stipulation, the condition that something is artistically valuable - when taken together with other stipulations that are precisely about the properties and processes associated with the object. However, we need not place much weight on this point. Our fourth response is designed to show how all that McCall stipulates can be maintained, allowing for creativity within the causal loop described. It accepts the possibility of the causal relations between the reproductions and the paintings that are specified, accepts the presence of artistic value, and also accepts McCall's view that artistic value entails creativity. (This is not to say that we do endorse all of these stipulations ourselves; just that there is a way of making them cotenable.) The question that drives McCall's puzzle is that of where the artistic creativity comes from. Our answer: it comes from the fact that the situation furnishes no defeaters for the judgement, made on the basis of encountering the paintings, that they are artistically valuable. We argued that whilst being copied from another work, or from work by another person, would be a defeater of the judgement, the work's being copied from itself or a reproduction of itself is not. In the absence of defeaters to render the process and the paintings uncreative, the positive evaluation of the paintings remains merited.

McCall's reply to our paper also includes a variant on his question of where the artistic creativity comes from: "What is the source of the artistic genius that the 21st century works exhibit?' (McCall's use of the term 
'artistic genius' did not appear in his original version of the argument.) Both 'genius' and 'creative' are terms that can be associated both with artworks and with the acts or capacities of artists. McCall says that the paintings exhibit artistic genius (associating genius with objects); that no artistic creativity is needed for what the artist does (associating creativity with acts or capacities); in asking 'where the element of ARTISTIC CREATIVITY comes from' (McCall's emphasis), he may be treating creativity as something present in the whole situation, without obviously associating it either with the artist's activity or with the paintings themselves. There are a couple of ways of framing the answer to the question of what source the artistic genius exhibited by the paintings has. First, insofar as for a painting to exhibit genius is for the artist to have exhibited their genius through painting, then the source of the artistic genius exhibited by the paintings in McCall's scenario must be the artist. In that case, the scenario shows that you can be a genius by copying from your own works (however 'fifth-rate' you were when you were trying to do something else). If that were the wrong result, then McCall would not be at liberty to set up the case as one where the paintings exhibit artistic genius. A second way of answering the question 'What is the source of the artistic genius that the 21 st century works exhibit?' is to say that the source is the whole causal loop, for the reason that no events within the loop are defeaters of the judgements of value made on the basis of seeing the paintings.

Thus, although McCall is quite right to say that the 'example of designing and building a time machine does not answer this question' - it was not intended to - we believe that the question has been answered. In the process, we hope also to have supported part of McCall's claim, that his puzzle is distinct from other puzzles of time travel. The novel features of McCall's case are about value. Whilst McCall says little about how this value gets to be tied to the artistic process, we hope to have set out what sort of connection between them can facilitate the scenario McCall describes; from which, we also get answers to McCall's key question.

Let us end on two further points which develop the discussion. Since McCall's reply focuses on the relationship between his cases and cases like that of the time machine and the plans, it is worth noting that just as artistic creativity is valuable, so too can scientific creativity be valuable (and 
creativity in engineering, and creativity in mathematics, and so on). Thus, time machines and plans can also be regarded as objects with a value linked to creativity. So it will sometimes be possible to generate a case like McCall's from a case like that of the plans for a time travel machine, once the value of something within the loop is made salient.

Finally, McCall's story treats the artist's paintings and the critic's reproductions as asymmetrical. The paintings have aesthetic value, whereas the reproductions 'reflect' it, and the artist is said to be 'copying on canvas the reproductions', suggesting that the reproductions are not themselves on canvas (p.647). Let's add a further spin to the case by considering a version where the critic produces his 'reproductions' by doing just what the artist does, carefully copying from the artist's paintings onto canvas. In this case we have two instances of the paintings, both of which are also reproductions. Does this version create any new challenges for our solution? Since the artist's paintings are copied from the critic's, and the critic's from the artist's, the paintings are copied from another person's work (assuming a version where the critic is not the artist). Would this furnish a defeater for the positive judgements made based on encountering the paintings? No. What makes copying from another's work a defeater of positive judgement is that the admiration bestowed on the copier is actually owed to the other person whose work they copied. But in the case in point, admiration does not properly rest with another person. Since the critic's work from which the artist copied is itself a copy of the very work the artist is making by copying it, the admiration owed to the critic from whom the artist copied is in turn owed to the artist from whom the critic copied, and so on (and vice versa). Perhaps it is even appropriate to describe this as a kind of (witting or unwitting) artistic collaboration. The potential ramifications of this case for debates in the philosophy of art also deserve noting: it bears not just on discussion concerning the value of replicas, but also on discussion concerning the multiple instantiation of artworks.

\section{References}

Manuscrito - Rev. Int. Fil. Campinas, v. 40, n. 1, pp. 281-287, jan.-mar. 2017. 
Bourne, C. and CADDick Bourne, E. "The Art of Time Travel: An 'Insoluble' Problem Solved." Special Issue of Manuscrito: Time and Reality I, edited by Emiliano Boccardi, 39 (4), pp. 305-313, 2016.

MCCALL, S. “An Insoluble Problem”. Analysis, 70, pp. 647-48, 2010. "Note on "The Art of Time Travel: An Insoluble Problem Solved." Special Issue of Manuscrito: Time and Reality II, edited by Emiliano Boccardi, pp. 279-280, 2017.

Manuscrito - Rev. Int. Fil. Campinas, v. 40, n. 1, pp. 281-287, jan.-mar. 2017. 